\title{
Macroeconomic impacts of climate change on the Blue Economy sectors of southern European islands
}

\author{
Zoi Vrontisi $^{1}$ (D) Ioannis Charalampidis ${ }^{1}$. Ulrike Lehr ${ }^{2,4} \cdot$ Mark Meyer $^{2}$. \\ Leonidas Paroussos ${ }^{1}$. Christian Lutz ${ }^{2}$. Yen E. Lam-González ${ }^{3}$. \\ Anastasia Arabadzhyan ${ }^{5}$. Matías M. González ${ }^{3}$. Carmelo J. León ${ }^{3}$
}

Received: 13 July 2021 / Accepted: 17 January 2022

(c) The Author(s), under exclusive licence to Springer Nature B.V. 2022

\begin{abstract}
Island communities are among the first and most adversely affected by the impacts of global climate change. Islands are vulnerable to climate change because of their isolated geography, large coastal areas, and low economic diversification. This paper presents a model-based evaluation of the macroeconomic impacts of climate change on the Blue Economy of southern European islands. We consider climate change impact chains on tourism, maritime transport, and electricity demand in a downscaled modeling framework for different climatic scenarios to the end of the century. Our findings show important economic losses in all climatic scenarios, yet economic damages under an RCP8.5 scenario more than doubled compared to a RCP2.6 pathway. Magnitudes of impacts vary across islands, depending on the level of economic diversification and geographic remoteness. The effects of climate change on the tourism sector are detrimental to the islandic economies, given the sector's complex value chain and dominant position in value added. Similarly, increasing electricity demand for cooling and water desalination puts additional stress on the economy of the islands.
\end{abstract}

Keywords Climate change $\cdot$ Climate costs $\cdot$ Economic impacts · CGE · Blue Economy · Islands

\section{Zoi Vrontisi}

zvrontisi@gmail.com

1 E3-Modelling, 11523 Panormou 70-72 Street, Athens, Greece

2 Gesellschaft Für Wirtschaftliche Strukturforschung mbH, Osnabrück, Germany

3 TiDES Institute, University of Las Palmas de Gran Canaria, Las Palmas, Spain

4 International Renewable Energy Agency, IRENA, Abu Dhabi, United Arab Emirates

5 Centre for Health Economics, University of York, York, UK 


\section{Introduction}

Island communities are among the first and most adversely affected by the impacts of global climate change (Lazrus 2012; Veron et al. 2019). Islands are vulnerable to climate change as they share relatively large coastal zones and feature valuable ecosystems and natural environments. Their level of biodiversity is high due to their levels of species endemism, unique functional traits, and evolutionary patterns (Taylor \& Kumar 2016; Russell $\&$ Kueffer 2019). In addition, islands are subject to more challenging adaptation processes due to their geographic remoteness. Most islands feature low economic diversification and share common economic challenges because of their distance from markets and the difficulties in enjoying the scale advantages arising from human and economic agglomeration (Weir et al. 2017; Linkov et al. 2014).

Climate change projections for islands around the world indicate that certain islands may disappear because of sea-level rise, while others will face a large reduction of coastal areas and land surface (Kelman 2018; Ourbak \& Magnan 2018; Kelman et al. 2019). Rising sea levels, changing precipitation and storm patterns, and increasing air and sea-surface temperatures can put additional stress on already limited island resources. Resilience and risk management strategies of these vulnerable lands need to be improved, also by deeper insights into the mechanisms of climate change impacts and economic damages (McMillen et al. 2014; Mcleod et al 2019; Sarker et al 2020). Both must be downscaled from global analyses to regional levels.

Blue Economy sectors, such as coastal tourism, coastal energy, fisheries and aquaculture, and maritime transport, are important to islands as sea-related economic activities have always been key to their socioeconomic development (Sarker et al. 2018; Bennett et al. 2019). The concept of Blue Economy refers to the sustainable development of the economic activities related to the oceans and the coastal areas and the improvement of coastal livelihoods. As such, sustainable growth of Blue Economy activities is a core part of recent strategies for green growth in the European Union and other regions around the world (Ruiz-Salmón et al. 2020; Lee et al. 2020; European Commission 2020a, b). At the same time, Blue Economy activities in islands face different and often larger challenges than in coastal regions (Spalding 2016; Hampton and Jeyacheya 2020). To this end, an assessment of the challenges related to climate change and Blue Economy sectors on an island level can provide valuable insights for the sustainable development and future resilience of island communities.

Applied macroeconomic analysis of climate change is a complicated task which is increasingly met with a combination of bottom-up sector-specific models and macroeconomic models (Ciscar et al. 2012; Ciscar et al. 2014; Feyen et al. 2020; Nordhaus 2017; Bosello \& Parrado 2020; Schinko et al. 2020). Because climate change is a global phenomenon, most applications have focused on the large-scale aggregation of geographical regions. However, if climate damage assessment is to inform adaptation policies, local results are needed. Downscaled modeling provides useful policy insights from a regional perspective based on unique vulnerabilities and socioeconomic characteristics. This paper develops a modeling approach of the economic effects of climate change impacts for relevant Blue Economy sectors of the southern European islands. Our macroeconomic modeling is downscaled to the island level to explicitly consider the economic characteristics of each island and focuses on tourism, maritime transport, and energy which are found among the most climate-sensitive and economically relevant sectors for the islands (SmithGodfrey 2016). 
This paper contributes to the literature on the assessment of climate change economic impacts by adopting a downscaled macroeconomic methodology for the Blue Economy sectors of islands' economies. The decision to study islands lies in the particularities of these territories with respect to the mainland and the coarse spatial resolution of many currently available projections of climate change impacts, both of which make it difficult to derive valid statements for islands (Leon et al. 2020) and pose unique challenges to their sustainable development and climate change adaptation efforts. The applied macroeconomic analysis of this paper aims to help the islands to fill in some of the knowledge gaps that still hinder the design of custom-tailored adaptation options and threaten the wellbeing of islandic populations.

\section{Methodology}

This paper considers climate change impacts for Blue Economy sectors with a detailed regional resolution focusing on nine southern European islands and archipelagos (Azores, Baleares, Canaries, Crete, Cyprus, Malta, Madeira, Sardinia, and Sicily), with two of them being EU member states. The focus is on islands located in the Mediterranean and the Atlantic Ocean. For this island-level economic analysis, islands' input-output tables have been constructed or updated to serve as a basis for the detailed analysis of the respective economy. Second, comprehensive economic outlooks to 2100 have been developed for the respective islands (Paroussos et al. 2019b) to allow for a dynamic analysis of the economic impacts of climate change. These outlooks include the main sectors of the island economies and the relevant Blue Economy sectors and comprise the reference case to which the climate change scenarios are compared. The latter scenarios are constructed with the introduction of direct economic impacts from biophysical climate impacts of matching levels of scale in the macroeconomic modeling frameworks.

\subsection{Modeling framework}

The modeling framework employed to estimate the macroeconomic impacts of climate change in islands involves two widely utilized macroeconomic models: an island-level application of the large hybrid general equilibrium model GEM-E3, GEM-E3-ISL, and an applied macro-econometric model, GINFORS. Both model versions applied for this analysis are presented in detail, including the key equations, in the respective report presented for the SOCLIMPACT project (Paroussos et al 2019b). Mercure et al. (2019) compare the different model features, one being a computable general equilibrium model (CGE) and the other a post-Keynesian macroeconometric one. Nikas et al. (2019) describe the differences and applications of both approaches as major representatives of climate-economy models. By applying two different theoretical approaches, we allow for an assessment of the underlying uncertainty due to differentiated economic assumptions, thus enhancing the robustness of the ex-ante assessment of climate costs. GEM-E3 is a CGE model that has been extensively applied in the impact assessment of environmental, energy, and climate policies (e.g., Karkatsoulis et al. 2017; Paroussos et al. 2019a, b; Vrontisi et al. 2020a, b). GINFORS is a world macroeconometric model which provides a deep mapping of country and sector structures utilizing the data set of the OECD Input-Output Database (Lutz \& Meyer 2009; Lutz et al. 2010; Wiebe and Lutz 2016, Meyer et al. 2018, Distelkamp \& Meyer 2019; OECD 2019). Both models have been originally developed to map mutual 
macroeconomic interdependences between national economies and have been further developed in this paper to enable the analysis of climate change impacts of Blue Economy sectors on an island level. To this end, regional databases have been constructed to ensure a harmonized input for both models.

\subsubsection{GEM-E3-ISL}

The GEM-E3-ISL is a multi-sectoral, recursive dynamic, single-country CGE model that provides useful insights into the economic system and the interactions of economic agents at the sub-national level. This is a single-region version of the GEM-E3 global CGE model (see E3Modelling 2017; Capros et al. 2013). GEM-E3 is written entirely in structural form and is founded on the principles of the microeconomic theory; agents follow a maximizing behavior and prices are endogenously calculated to balance. The economic agents that are individually represented in the model are as follows: firms, households, government, and the external sector. The model is dynamic and recursive over time, and the dynamics are driven by capital accumulation, infrastructure accumulation, population, and technical change. The model is suitable for comparative analysis since it ensures that in all scenarios the system remains in equilibrium. The single-region version of the large-scale GEM-E3 model was employed as more suitable for this analysis as islands are considered to be small economies that behave as price takers in the sense that their economic activity does not affect international prices, and thus, they assume that prices of imported commodities are given. Provided that bilateral trade data are not available on the island level, the choice of a single-region version does not compromise the quality of analysis. However, we note that there are certain limitations particularly with regards to primary factor mobility (i.e., labor migration and external financing) that force a less-flexible transition to the new scenario equilibrium. Nevertheless, the single-region model is smaller in size and thus requires less resources for simulations and allows for a large number of scenario simulations.

The GEM-E3-ISL model version identifies 14 production sectors for which a representative firm is assumed. Each producer maximizes their profits, which are defined as the difference between revenues earned and inputs' cost, subject to its production technology, while consumers maximize their welfare through their utility function. The production technology is represented by a constant elasticity of substitution (CES) function. Markets are assumed to be perfectly competitive which means that both consumers and producers act as price takers. Hence, firms maximize their profits by choosing the optimal mix between capital, labor, and intermediate inputs taking both the factor costs and the price of their products as given. The stock of productive capital in the economy is given in the current period but can change in the future through investment, bringing a dynamic feature in the model structure. Hence, when firms face increased demand for their product, they will increase their investments but the influence of the increased productive capacity on the economy will be more evident in the consequent periods. The labor market formulation allows for unutilized resources through involuntary unemployment, following the efficiency wages approach that is described by an empirical relationship between wages and labor supply. The model closure rule states that the agent's savings equal investments at all points in time. This is possible by the adjustment of the regional interest rate, which denotes for the case of the firm's regional differentials in the cost of financing. A demanddriven shock, such as a change in tourism revenues, apart from the direct impact on the activity of sectors will also induce a second-round of effects that derive from the response of primary production factor markets (i.e., the labor and the capital market). As wages and 
capital rents adjust to reach a new equilibrium point, resources move towards more profitable activities which record competitiveness gains due to changes in production costs. In this model application, capital and labor are not mobile beyond the regional level; i.e., each island is limited to its own capital and labor resources. The latter assumption implies a limitation to extra-islandic investments and interregional labor migration, thus not allowing for autonomous adaptation that could reduce economic costs.

\subsubsection{GINFORS}

GINFORS is a macro-econometric model that is based on the post-Keynesian theory where both sides of the market play an important role, unlike static input-output approaches (Hein 2017). Behavioral parameters are determined by econometric estimation of time series data. Since the economy is assumed not to be in equilibrium, markets do not clear, making it possible to contemplate both involuntary unemployment and idle capital stock. Furthermore, imbalances between supply and demand are more likely to be offset by demand-driven mechanisms rather than by price effects.

GINFORS is based on a deep mapping of country and sector structures (Lutz \& Meyer 2009; Lutz et al. 2010, 2012; Meyer et al. 2012). The GINFORS (global inter-industry forecasting system) model is a world trade model mainly based on OECD data, which consistently and coherently models bilateral exports and imports of 25 goods groups for 64 countries and one "rest of the world" region. It incorporates a macro-model, consisting of exports and imports, other core components of final demand (private and public sector consumption and investment), markets for goods, and the labor market, for each country. The models are also divided into 36 goods categories in accordance with the latest OECD (2019) internationally harmonized input-output (IO) tables. Each national model is linked to an energy model, which determines energy conversion, energy generation, and final demand for energy for 19 energy sources disaggregated by economic sector building on IEA (2019) energy balances. The model takes into account technological trends and price dependencies.

Given this complete mapping of well-defined accounting and balancing interrelationships, the model can provide a thorough account of complex response relationships on a macroeconomic scale in each simulation. This modeling philosophy corresponds to the tradition of INFORUM-type models (Almon 1991) and features post-Keynesian system properties. Considering these system properties, GINFORS-E is thus comparable to the E3ME model developed and maintained by Cambridge Econometrics (Pollitt and Mercure 2018). Moreover, the model provides extensive insights into the globalization effects of international trade developments.

\subsection{Development of island-level databases}

The need to apply subnational analysis comes as a consequence of spatial heterogeneity and at a cost of data availability. The latter is critical to capture the key characteristics of each island economy and to ensure a harmonized input for both models used for the analysis. For the purposes of this research, consistent, up-to-date, and harmonized socioeconomic island-level datasets were developed to serve as an input to both models. Both models are essentially based on applications of input-output accounting frameworks, while employment data and Tourism Satellite Accounts (TSAs) were also a key part of the newly developed databases. To construct the databases, all available data was used; however, as 
reporting years, sectoral disaggregation, and methodological approaches were not consistent across islands, updates of existing databases were necessary. The new databases have a harmonized base year (2015) and sectoral disaggregation (14-sector disaggregation, see Table 5 of Supplementary Information). The conversion of existing raw data into our proposed classification structure required several methodological steps, including RAS procedures, which ensure consistency between the entries of the input-output matrices and row and column totals known from statistics. RAS is a well-known method for data reconciliation (see Memobust 2014) and is an iterative scaling method whereby a non-negative matrix is adjusted until its column sums and row sums are equal to some pre-specified totals. Raw data, including gross value added, sectoral gross output, intermediate consumption, compensation of employees, and imports and exports, mostly available at a high aggregation level, were gathered from regional and national statistical offices, Eurostat structural business statistics (SBS) database, GTAP database (Aguiar et al. 2019), and relevant publications. For the treatment of data gaps, national statistics were also used for the purposes of further sectoral disaggregation, final and intermediate demand, and production structure. National TSAs were also used to produce island-level ones. More details on the development of island-level IOs and TSAs can be found online in the report prepared for the SOCLIMPACT project (Meyer et al. 2019).

\subsection{Modeling climate change impact chains}

Damages are assessed with a bottom-up approach that utilizes regional climatic models and involves interdisciplinary work based on the concept of climate change impact chains (Arabadzhyan et al. 2020). This concept emphasizes the notion that risks are the results of complex interactions between hazards, exposure to natural, social, and economic subsystems and the degree of their vulnerability to climate shocks (IPCC 2012). All quantities along the modeling chains are estimated specifically on the scale of the respective islands and for all the Blue Economy sectors considered.

Downscaled climate change projections were conducted for each island by using an ensemble of 21 Atmosphere-Ocean coupled General Circulation Models (AOGCMs). Following Jordá et al. (2020), the dynamic contribution inside the basin from the global models was substituted by the estimate obtained from an ensemble of regional ocean climate models, from the MedCORDEX online database (https://www.medcordex.eu/). The climatic projections are linked to RCP2.6 and RCP8.5 IPCC emission scenarios and considered two time horizons: the near (2040-2060) and the distant (2080-2100) future. The climatic projections were used as inputs to a range of different economic evaluation approaches that are described in detail in the Supplementary Information. In that way, climatic impacts are translated into direct economic damages or other types of biophysical damages that are incorporated into the macroeconomic models (e.g., tourism expenditure for the tourism sector, or energy demand for cooling for the energy sector). The two macroeconomic models (GEM-E3-ISL and GINFORS) use a harmonized input of direct impacts associated with the climate hazards of selected impact chains. The methods used to incorporate the damages into the macroeconomic modeling frameworks are described in more detail below.

With respect to the time frame, the macroeconomic models follow the approach of the climatic simulations; hence, two periods are considered: (i) the near period refers to the years from 2040 to 2060 and (ii) the distant period (only in GEM-E3-ISL) refers to the years from 2080 to 2100 . All climate impact scenarios are estimated for two different 
climatic projections, namely for RCP2.6 and RCP8.5 concentrations, indicating the climate impacts under a scenario that aims to keep global warming likely below $2{ }^{\circ} \mathrm{C}$ above preindustrial temperatures and under a baseline scenario without additional efforts to constrain emissions respectively.

\subsubsection{Impacts on tourism}

The studied islands rely heavily on the tourism sector while at the same time rate among the most popular destinations for EU and non-EU residents. Climate impacts are expected to affect tourist flows to the islands. For example, the Mediterranean region is expected to face less favorable conditions given predicted raises in temperature caused by climate change, which are likely to become increasingly important in the long term. The number of so-called hot days with temperatures above $35^{\circ} \mathrm{C}$ is expected to increase more significantly in certain areas, for example, the Balearic Islands and Crete (Arabadzhyan, et al. 2020). This situation will cause important changes in the tourism visitation seasonality of these islands (Primo et al. 2018).

The bottom-up evaluation of climate change impact chains for tourism is described in detail in the Supplementary Information and makes use of (i) transfer functions from the literature, (ii) survey data, (iii) big data analysis, and (iv) experts' assessment. This bottomup process evaluates the changes in total touristic expenditures with respect to a scenario without climate change consideration, which is then used as an input to the macro models. The bottom-up inputs that are incorporated in the macroeconomic models are presented in the Supplementary Information.

As described in the Supplementary Information, different impact chains are considered for tourism. Our assessment of climate change-induced impacts considers (i) seagrass loss, (ii) forest fires, (iii) beach reduction, (iv) thermal comfort, and (v) vector diseases. The GEM-E3-ISL model performs simulations for each of the abovementioned impact chains as well as for a combination of all hazards referred above.

In GEM-E3-ISL, the tourism sector is represented as an individual agent along with households, firms, and the government. Tourists' consumption patterns follow the preferences indicated in the Tourism Satellite Accounts and expenditures are exogenously specified for the single country model region. The input from the bottom-up climate impact chain evaluations is directly incorporated into the model through this exogenous touristic demand. The allocation of tourism expenditures to different product categories and services, which is based on the island-specific Tourism Satellite Accounts, establishes the link between the exogenous touristic demand and the input-output tables of the domestic economy in the GEM-E3-ISL model. This allocation of touristic demand to specific demand for goods and services, and its changes thereof, drives the island's sectoral economic activity, employment levels, and trade.

In the extended GINFORS model, tourists' expenditure is modeled as the final demand of travelers for goods and services on the respective island. Climate change yields changes in tourists' demand and expenditure patterns, which enters the model as an exogenous change. The demand decrease leads to changes in demand for intermediate goods from the respective industries and services, and thus to demand changes throughout the economy. The production of the respective goods changes with demand, with prices and import shares playing an important role in the sectoral effects. Employment losses are derived from the respective changes in the production of goods and services. 


\subsubsection{Impacts on maritime transport}

Maritime infrastructures, i.e., harbors and ports, are affected by climate change through waves, storm surges, and other extreme weather events (hails, strong rain, etc.). Our assessment identified as the main relevant damage channel for the islands to be the impacts on infrastructure due to sea-level rise. The amount of investment necessary for the maintenance of port operability (keep ports operating (KPO)) is used as input to the macroeconomic models. This type of input can be considered in two ways in the context of macroeconomic models: (i) as adaptation investments necessary to keep the ports operational after the climate events have occurred or (ii) as damage to port infrastructure which indicates overall destruction of the available capital stock, without however considering the potential impacts on the supply of goods to the islands (Christodoulou et al. 2019). Bottom-up inputs to macroeconomic models are presented in the Supplementary Information.

In the GEM-E3-ISL model, this input is incorporated through the second channel described above, which is namely considered a damage to port infrastructure that reduces the capital stock of the maritime sector. Due to the assumption of perfectly mobile capital across sectors, damages in the capital stock of the maritime sector result in a loss of capital for the entire economy. In the CGE context, losses in capital stock increase the cost of capital and as investments follow Tobin's Q approach, where firm compares its user cost of capital with its replacement cost to formulate its investment decision, higher capital costs bring higher investment demand. At the same time, higher capital costs increase production costs with negative impacts on competitiveness.

In the GINFORS model, investment in infrastructure tends to exhibit positive effects, creating additional demand for goods and services. This effect is often referred to as the defensive GDP effect. To integrate the negative effects on the islands from climate change damages to ports and the additional efforts to keep the islands supplied with imported goods, these effects are built into transport costs. Thus, they have a negative macroeconomic effect on the model. In maritime transport, the port infrastructure affects transport costs to a large extend. To implement the KPO expenditures in GINFORS, transport costs are adjusted to the respective islands accordingly.

\subsubsection{Impacts on energy}

For the energy sector, we consider the effects of climate change on energy demand of the islands. This is beyond the scope of the Blue Economy terminology that considers only the production of coastal energy. In particular, changes in energy demand are identified through increased electricity demand for cooling and for desalination. The assessment of the economic impact of climate change on the energy sector focuses (i) on the evaluation of the additional demand of energy to lead with higher temperatures during the season prone to heat and (ii) on the estimation of the costs associated with higher consumption of water to compensate more elevated temperatures across the different domains of humans' activities (housekeeping, gardening, etc.). Bottom-up inputs to macroeconomic models are presented in the Supplementary Information.

In GEM-E3-ISL, the increase in energy demand due to cooling needs is simulated both for industries and services as well as for households. For sectorial activity (e.g., the cooling requirements of the service sector), relevant input is incorporated as changes in the intermediate demand for electricity while in the case of households it is incorporated as a 
change in the compulsory consumption of electricity. The former implies that along with households, tourist accommodation will require more electricity per night as the increase in temperature will increase the overall operation of cooling services. Households will have to increase their overall electricity consumption to maintain the same level of utility given the increased occurrence of heatwaves. In addition, decreased precipitation rates imply a higher supply of water from desalination facilities. The latter uses electricity-intensive processes for providing freshwater. This is modeled via the changes in demand for electricity of the non-market services and the water sector.

In the extended GINFORS model, additional energy demand increases the turnover of the utilities and demand for intermediate goods increases as well. This exerts a positive impact. However, they have to expand their capacities over time to meet this demand. For instance, the amount of PV modules installed on rooftops of residential households, restaurants, hotels, and public buildings will be increased, or existing generation is expanded. Either response will increase the price and thus expenses for electricity and cut into the budgets of households and the profits of hotels and restaurants. Turnover of utilities increases. The net effect varies across islands.

\subsection{Scenario framework}

The scenario framework includes a reference scenario and a set of climate impact scenarios. The reference scenario features no climate impacts or additional climate policies. It represents the implementation of current climate and energy policies; however, the feedback of the islandic emission trajectories to the global carbon budget and hence the linkage to the RCP trajectories is not considered. Climate impacts are considered exogenous inputs. The macroeconomic outlooks for each island and the methodology followed to develop these are presented in detail in the report prepared for the SOCLIMPACT project (Paroussos et al 2019b). The GDP growth rate of each island is aligned with the respective national GDP based on Eurostat's Ageing Report 2018 (European Commission 2017) until 2070 and on the author's calculations for the period from 2070 to 2100. Population projections on an island level are provided by Eurostat for the period 2020-2050 (dataset proj_18r) while for the period 2050-2100, these are estimated according to the national projections provided by Eurostat (dataset proj_18np). The outlooks assume that the regional unemployment rate will decrease and in the long term will converge to the natural rate of unemployment. Outlooks are consistent with an SSP2 trajectory and are based on past evidence and future trends.

The sets of climate impact scenarios are classified into the following categories:

1. Tourism: an assessment of the impact chains related to seagrass loss, forest fires, beach reduction, and thermal comfort,

2. Energy: an assessment of the impact chains related to increased electricity consumption for cooling purposes and water desalination,

3. Maritime transport: an assessment of the impacts of climate damages on port infrastructure,

4. Aggregate: climate impacts induced by all impact chains that are analyzed in this paper, namely for tourism, electricity demand, and maritime transport.

Supplementary Information presents a summary of the scenario inputs that are incorporated in the models. For each island under analysis, the GEM-E3-ISL model has performed 
one aggregate and 11 sub-scenarios for each climatic scenario, resulting in 24 scenarios per island and 216 scenarios in total. The sub-scenarios allow for a decomposition analysis by impact chain to define the key drivers of macroeconomic impacts and identify which climate impacts affect the economies of the respective islands. Results of the sub-scenarios by impact chain for tourism and energy that have been simulated by the GEM-E-ISL model are presented briefly in the results section, particularly for tourism and energy impact chains. The GINFORS model has performed the aggregate scenarios by island for each climatic scenario, resulting in 2 scenarios per island and 18 scenarios in total.

\section{Results and discussion}

The macroeconomic assessment of climate impacts on the Blue Economy of the southern European islands shows GDP losses under both climatic scenarios for both models. Results indicate that climate impacts have a negative effect on economic activity, even if a subset of impacts is taken into consideration. Signs of GDP results are the same in all islands for both models, with the exception of two islands in the RCP2.6 scenario, and magnitudes are comparable, thus adding to the robustness of the findings. Results are described in detail below, presented first for the aggregate scenario and then by impact sector, as changes from a reference scenario with no incorporation of climate impacts.

The GEM-E3-ISL CGE model indicates that GDP losses range from -0.2 to $-2.6 \%$ in 2050 and -0.3 to $-6.0 \%$ in 2100 under the RCP2.6 scenario and from -0.6 to $-5.7 \%$ in 2050 and -1.4 to $-13.8 \%$ in 2100 under the RCP8.5 scenario. The GINFORS macroeconometric model shows that GDP losses range from 0.2 to $-3.8 \%$ in 2050 under RCP2.6 scenario and from -1.6 to $-7.3 \%$ in 2050 under the RCP8.5 scenario. Private consumption and hence welfare are negatively affected in all climatic scenarios for both models as income reduces due to the drop of touristic activity and overall economic damages. In addition to lower consumption levels, the increasing demand for cooling and desalination results in a higher share of disposable income to be directed towards electricity consumption; hence, demand for other goods and services drops causing additional pressure on the local economy.

The magnitude of impacts is comparable between the two models, with the macroeconometric GINFORS model showing slightly larger effects. The ranking of impacts across islands is shown in Fig. 1 for both models, indicating robust findings for some islands and larger discrepancies for others. For example, in the RCP2.6 scenario both models find that the Canary Islands have the highest GDP losses, followed by the Balearic Islands. However, results for Malta, Sardinia, and Madeira differ, with GINFORS reporting higher impacts than GEM-E3-ISL. This is explained by the fact that the GEM-E3-ISL model features autonomous adaptation mechanisms through price adjustments and demand responses that can mitigate costs projected by the macro-econometric framework. In the RCP8.5, these differences are more pronounced due to the higher intensity of impacts, as seen for example for Malta, Azores, and Sardinia. Nevertheless, the results are robust in showing that the Canary Islands show the largest GDP losses, around 6\% compared to reference GDP levels, followed by Crete and the Balearic Islands. Overall, Fig. 1 shows that in both models, economic losses under the RCP8.5 scenario more than double compared to the respective RCP2.6 losses for most islands, following the higher intensity of biophysical damages. 


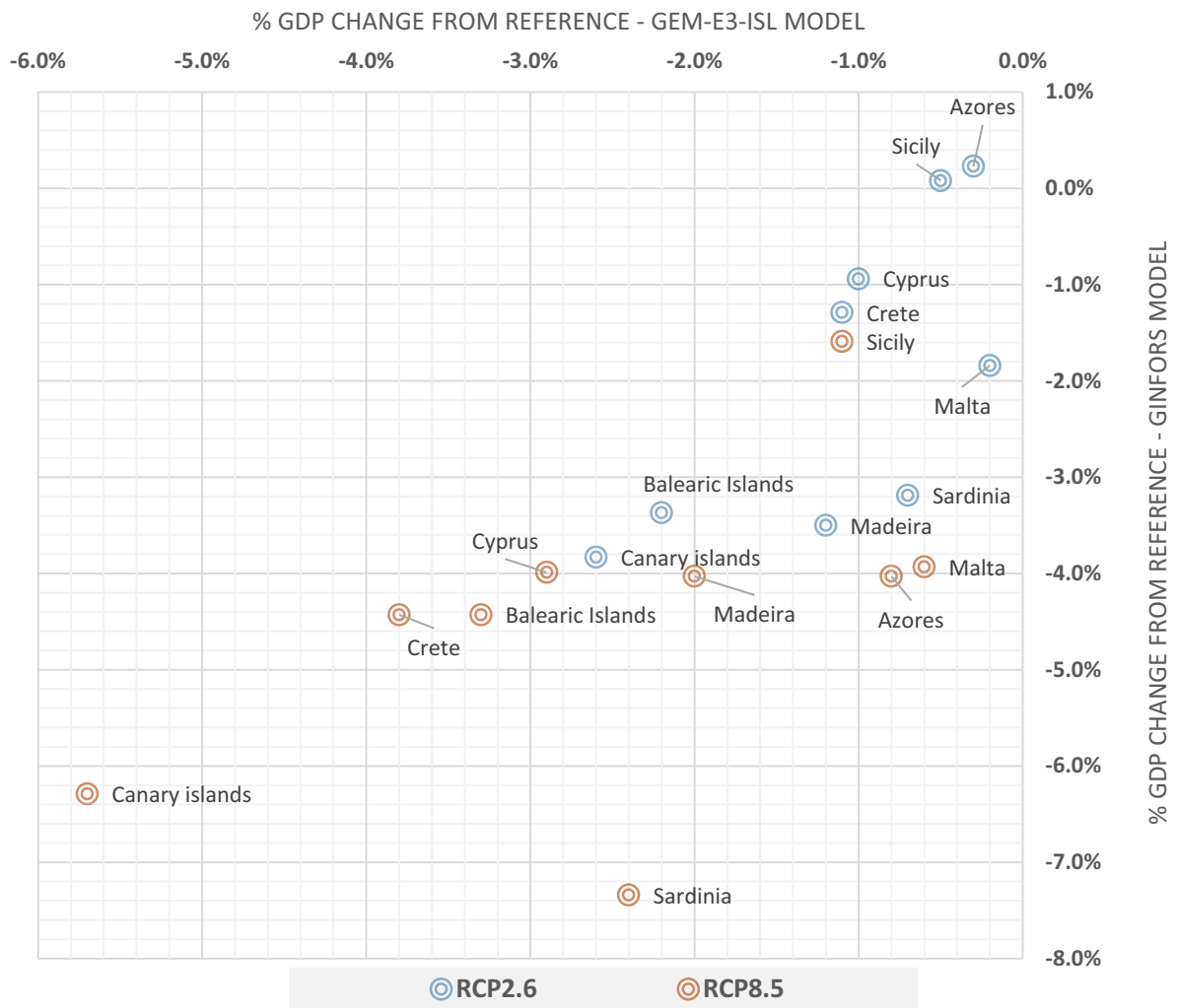

Fig. 1 GDP impacts for the aggregate RCP2.6 and RCP8.5 scenarios in 2050 by model; source: GEM-E3ISL and GINFORS models

The level of economic losses differs by island due to the intensity of direct climate impacts as well as the economic vulnerability. The key drivers of the latter are the geographical remoteness and the economic diversification of each island. For instance, the Canary Islands that are geographically remote and have low economic diversification with a high share of tourism in total value-added show significant economic losses due to climate impacts. Islands characterized by a high share of tourism in total value added, e.g., Canary Islands, Balearic Islands, and Crete, rank high in economic losses on Blue Economy sectors. GEM-E3-ISL results show that islands with proximity to the mainland, like Malta, Sicily, and Sardinia, have less intense economic impacts. Particularly with respect to the impacts due to electricity demand for cooling and desalination, geographic remoteness hinders the electrical interconnection of the islands with the mainland and thus amplifies the economic damages.

GINFORS simulations consider that investments in the expansion of energy systems will generally generate positive growth impulses, assuming that these investments are additional. On the contrary, in GEM-E3-ISL, the additional investment requirements have crowding-out effects due to the assumption that capital and labor demand is met by the island's own resources in line with the assumption of immobile capital and labor across regions. On the other hand, for both models, the modeled changes in the tourism and transport sectors dampen economic growth in the islands under consideration. Nevertheless, the 
magnitude of impacts is comparable between the two models, with the macro-econometric GINFORS model showing slightly larger effects due to the assumption of unresponsive markets.

\subsection{GEM-E3-ISL results}

Sea level rise and other coastal-related damages are detrimental to the marine environment and the beach condition of the islands. Increasing temperatures, increasing occurrence of heatwaves, and reduced precipitation have an adverse effect not only on human thermal comfort but also on the occurrence of forest fires. Tourist revealed preferences show a sensitivity of touristic expenditures to climate-related changes, with an average drop of expenditures by $-13.4 \%$ in the RCP 2.6 climatic scenario and an average of $-22.3 \%$ in the RCP8.5 scenario compared to the reference (see Tables 1 and 2 in Supplementary Information). Tourism has a high share in total value added for most islands and features a complex value chain; thus, impacts on tourism are the largest contributors to total GDP losses for the majority of islands (Fig. 2). We find that islands characterized by a high share of tourism in total value added, e.g., the Canary Islands, Balearic Islands, and Crete, have higher economic losses from climate impacts on Blue Economy sectors. Impacts related to beach reduction are the main drivers of tourism expenditure decline for all islands, followed by forest fires (Fig. 3).

Tourism-related industries are labor-intensive; thus, lower activity levels exert negative pressure on the labor market, leading to lower wages and higher unemployment. The wage income of households falls leading to lower consumption. GEM-E3-ISL results indicate that the sharp reduction in tourism arrivals can bring cumulative GDP losses over the 2040-2100 period equal on average to $1.2 \%$ in the RCP2.6 scenario and $3.2 \%$ in the RCP8.5 scenario compared to the reference levels (Fig. 2). The maximum GDP losses due

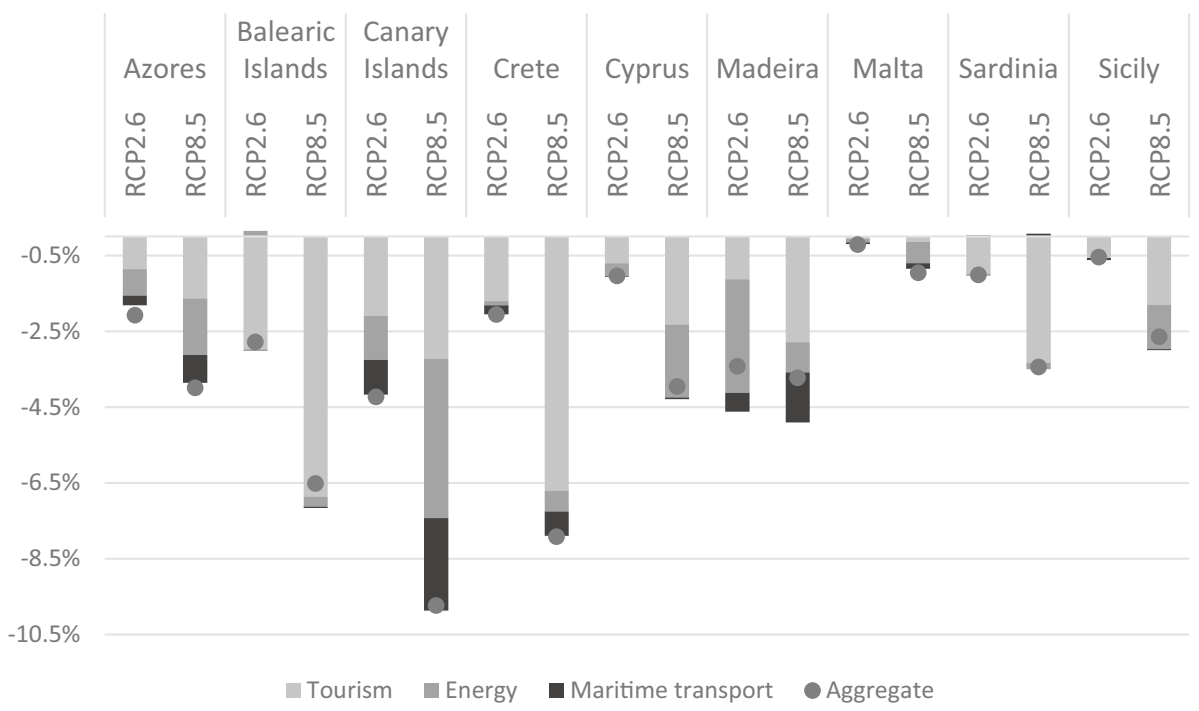

Fig. 2 Cumulative GDP changes for the 2040-2100 period by impact sector (stacked columns) and in total (dot) RCP2.6 and RCP8.5 scenarios for each island; source: GEM-E3-ISL model 


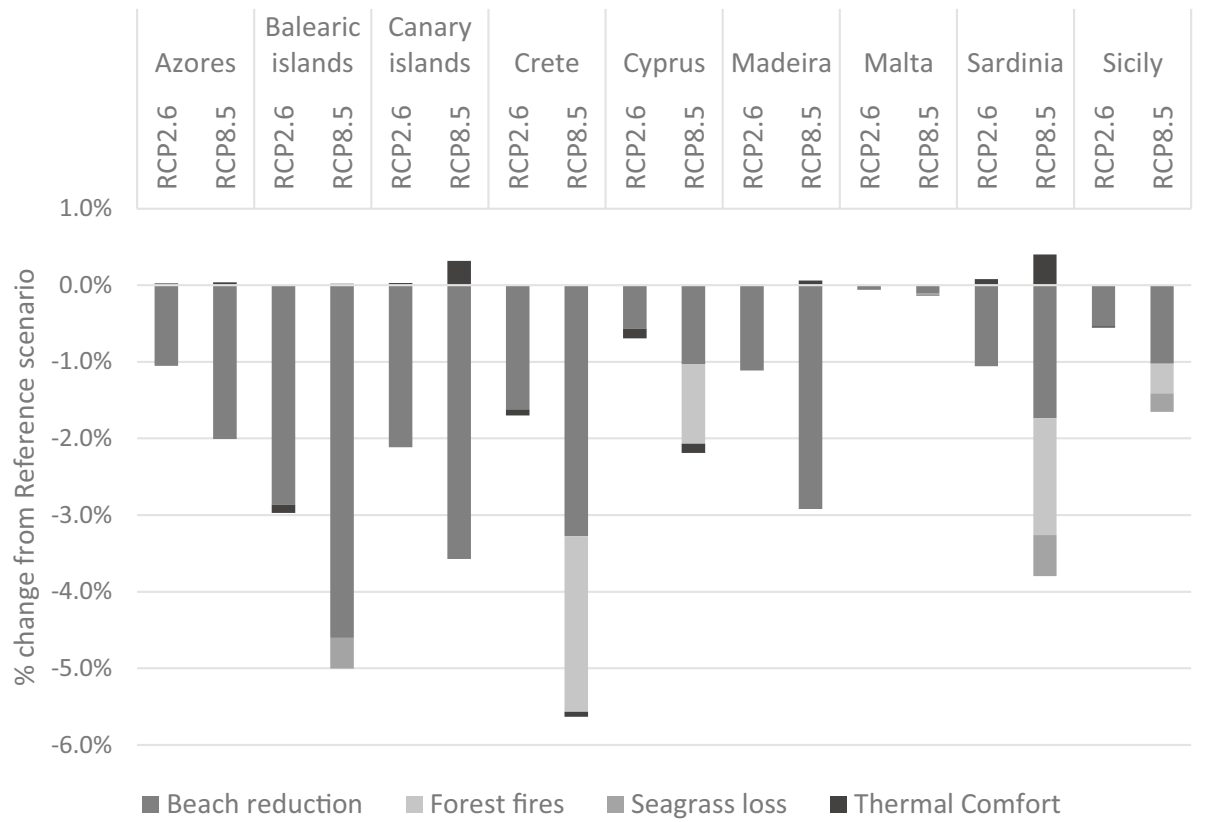

Fig. 3 Cumulative GDP changes for the 2040-2100 period by impact chain of the tourism sector in the RCP2.6 and RCP8.5 scenarios for each island. Source: GEM-E3-ISL model

to climate impacts on the tourism sector can reach $6.9 \%$ of reference GDP levels for islands with high shares of tourism in their value added (e.g., Balearic Islands, Crete).

High temperatures, humidity, frequent heat waves, and low precipitation rates will affect the living conditions of the domestic population and tourists, leading to an increased demand for cooling and water desalination, both of which are energy-intensive processes. We project that climate change will cause an average increase of electricity demand by $10 \%$ in the RCP2.6 scenario and by $24 \%$ in the RCP8.5 (see Tables 4 and 5 in Supplementary Information). In the GEM-E3-ISL model, this sharp increase in demand increases electricity prices and adds pressure to the island's limited resources. Geographic remoteness is a key driver of these results as it hinders the electrical interconnection of the islands with the mainland, thus increasing the costs associated with higher electricity demand. The latter put pressure on the island's capital requirements and induce crowding-out effects, given the assumption of immobile capital across regions. The scenario implementation does not assume any financing tool, as for example the funding of power generation facilities from central governments, which potentially could alleviate the crowding-out effects. In addition, while existing interconnections have been taken into consideration (e.g., Malta to Italy), we note that forthcoming ones have not been considered (e.g., Crete to the Greek mainland). Interconnections to the mainland can enhance the adaptive capacity of the islands to the changing electricity demand due to climatic changes. While investments increase in order to meet higher electricity demand, higher prices bring competitiveness and GDP losses, as households spend a larger share of their disposable income on energy services. GEM-E3-ISL results show an average cumulative GDP loss over the 2040-2100 period equal to $0.6 \%$ of reference GDP in the RCP2.6 scenario and $1.2 \%$ in the RCP8.5 scenario (Fig. 2). We find that higher electricity demand for cooling purposes is the key 
driver of these results for most islands; however, the Canary Islands and Malta are exceptions to this as increasing water shortages increase demand for desalination (Fig. 4).

Finally, the analysis looks at the impacts of climate change on port infrastructure. The risk of stopping or slowing maritime transport mainly arises from the risk of ports becoming non-operative. The latter is primarily linked to sea-level rise, as discussed in the Supplementary Information. The damages of port infrastructure, expressed as a \% share of reference GDP, are on average $-0.2 \%$ for the RCP2.6 scenario and $-0.5 \%$ for the RCP8.5 one and result in lower capital rents and higher maritime transport prices. GEM-E3-ISL results show (Fig. 2) that the impact of climate change on port infrastructure can affect the overall economy with average cumulative GDP losses over the 2040-2100 period equal to $0.2 \%$ of reference GDP in the RCP2.6 scenario and 0.6\% in the RCP8.5 scenario, without taking into consideration potential port closures and severe disruptions of supply chains.

Overall, GEM-E3-ISL simulations for the aggregate scenarios that include all impact chains, namely incorporating climate damages into tourism, electricity demand, and maritime transport, indicate a capacity of the system to adapt to multiple impacts by showing GDP losses equal or lower to the sum of each sector-specific scenario. For example, as demand lowers due to less tourism arrivals, the impact of higher electricity prices has a lower effect on the overall economy. Similarly, a decline in touristic demand releases labor and capital that are then available to cover the higher demand for electricity.

Macroeconomic implications are significant under both climatic scenarios; however, economic losses under the RCP8.5 scenario are twice the magnitude of losses in the RCP2.6 for most islands (Fig. 5). Results vary when comparing long-term losses of the RCP2.6 scenario with medium-term losses of the RCP8.5 scenario. The time profile of impacts is directly associated with the scenario assumptions, namely the inputs from estimated biophysical impacts. GDP losses are more pronounced in the long term due to the

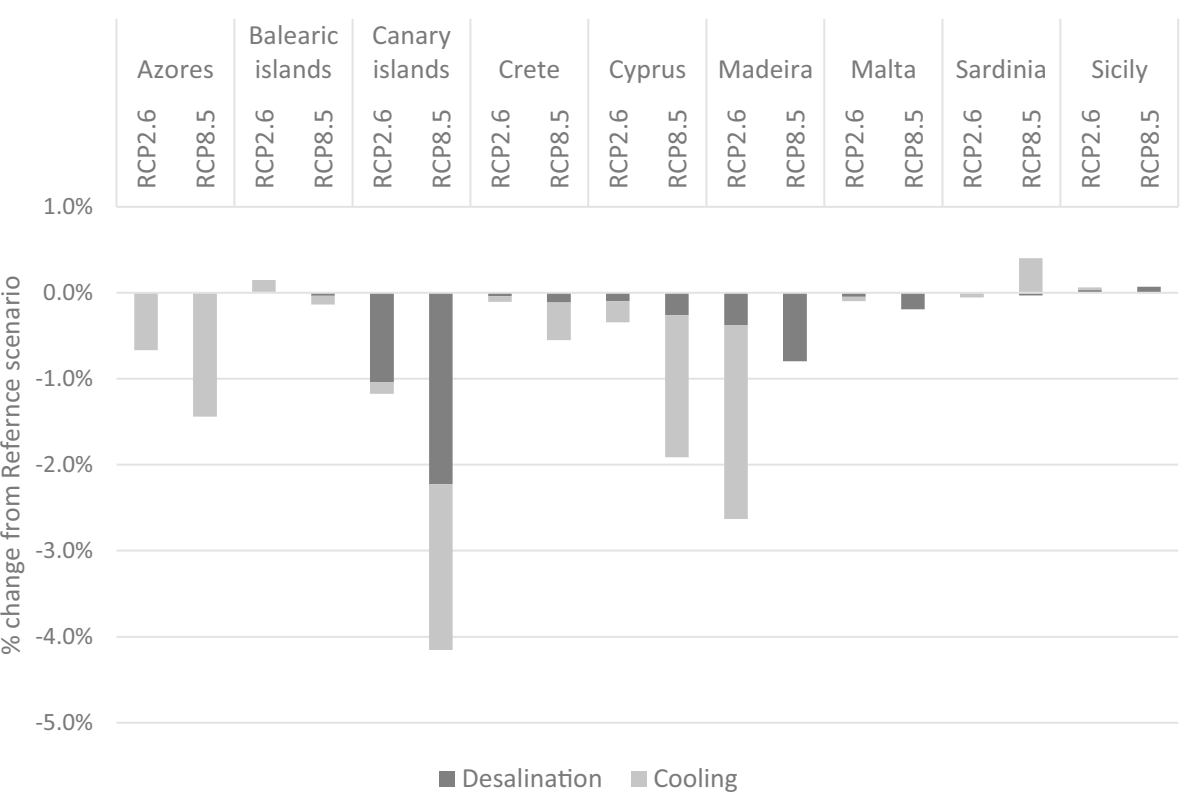

Fig. 4 Cumulative GDP changes for the 2040-2100 period by impact chain of the energy sector in the RCP2.6 and RCP8.5 scenarios for each island. Source: GEM-E3-ISL model 


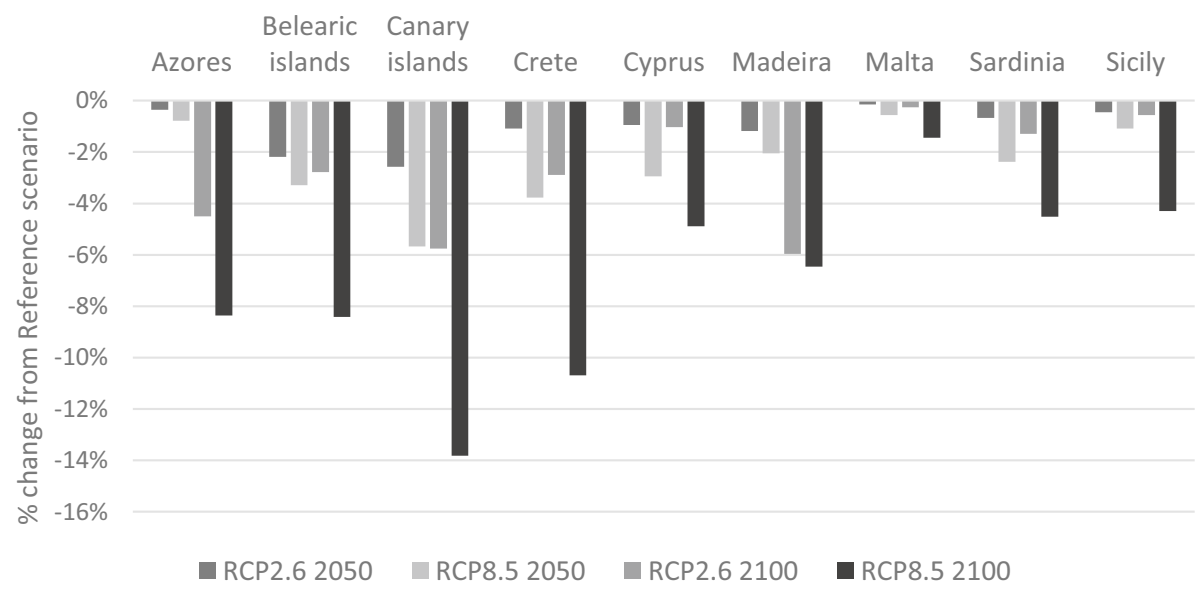

Fig. 5 GDP changes by island for the aggregate RCP2.6 and RCP8.5 scenario in 2050 and 2100. Source GEM-E3-ISL model

projected intensification of climate impacts; however, the scale of this effect differs across islands.

Private consumption expenditures fall significantly over the examined period as household income decreases because of low touristic activity. Furthermore, the scenario specification implies that a larger share of disposable income will be directed towards electricity consumption; hence, demand for other goods and services falls creating additional pressure on the local economy. This in turn will lead to lower investments, as firms do not foresee profitable conditions that would incentivize the expansion of their production capacity. Results indicate a positive impact on regional trade balance for most islands as lower consumption affects demand not only for domestic but also for imported goods and services, while exports increase as lower demand for domestic goods and services and lower touristic activity results in higher availability of resources, thus more competitive production costs. This effect is in line with what is observed when firms meet unfavorable conditions in the domestic market and become more extroverted in order to find markets for their products.

With respect to the labor market developments, the simulation results show decreased employment levels for both climatic variants (RCP2.6 and RCP8.5) and for the entire period (see Supplementary Information). The employment losses recorded are attributed mainly to the decreased employment in the labor-intensive tourism sectors but are also linked to the competitiveness losses due to higher electricity prices.

\subsection{GINFORS results}

The macroeconometric GINFORS model allows for mid-term projections of economic impacts running up to 2050. Despite the usual short-term analyses, macro-econometric models have been used in different applications until 2050 (European Commission 2020b, European Commission 2021, Meyer and Ahlert 2019). Behavioral parameters are based on time series estimates since 1990 . Due to the longevity of the capital stock in the tourism, maritime infrastructure, and energy sectors, simulations for the next three decades appear to be adequately covered by this. Shocks from climate change and 
adaptation to it also occur differently up to 2050. In this respect, the use of a macroeconometric model also seems appropriate over this time frame, as the model answers the question of how the economic system reacts to these ever-changing shocks over time. GDP losses due to climate change impacts on the Blue Economy sectors range from -0.16 in 2030 to $-3.8 \%$ in 2050 under RCP2.6 scenario and from -0.3 in 2030 to $-7.3 \%$ in 2050 under the RCP8.5 scenario (Fig. 6). Economic losses under RCP8.5 scenario are much higher than those under the RCP2.6 scenario for all islands. For most islands, the impacts under scenario RCP8.5 are much higher than those under scenario RCP2.6 in relative terms.

The GDP losses are driven by the impacts of climate change on tourism, energy, and maritime transportation in the different islands, thereby impacting consumption and investment decisions of economic agents throughout the economic systems of the islands. Impacts on investment are positive in most of the islands under both scenarios of climatic conditions, because of the need to push forward investments on maritime infrastructure restoration and renewable energy systems independent from the mainland. Average impacts on investment across islands range between $0.22 \%$ for RCP2.6 in 2030 and $1.3 \%$ for RCP8.5 in 2050; i.e., damages increase and more investment is needed over time and for the most extreme climatic scenario. Impacts on consumption are always negative and become higher for those islands with a higher dependence on international tourist arrivals, such as Malta, the Canary Islands, Azores, and Sardinia. Average impacts on consumption across all islands range between $-1.08 \%$ for RCP2.6 in 2030 to $-5.5 \%$ for RCP8.5 in 2050.

The negative impacts on GDP increase over time, ranging from an average impact across islands of $-1.04 \%$ in 2030 for scenario RCP 2.6 to $-4.4 \%$ in 2050 under scenario RCP8.5. The rate of growth of impacts diminishes until 2050 for most islands. On average, the increase of GDP losses across islands under scenario RCP 2.6 between 2030 and 2040 is $-0.6 \%$, becoming a $-0.3 \%$ increase between 2040 and 2050. A similar trend of diminishing marginal increases in GDP losses across islands is found for scenario RCP8.5, although with higher magnitudes ( $-1.3 \%$ for $2030-2040$ followed by $-0.7 \%$ for $2040-2050$ ).

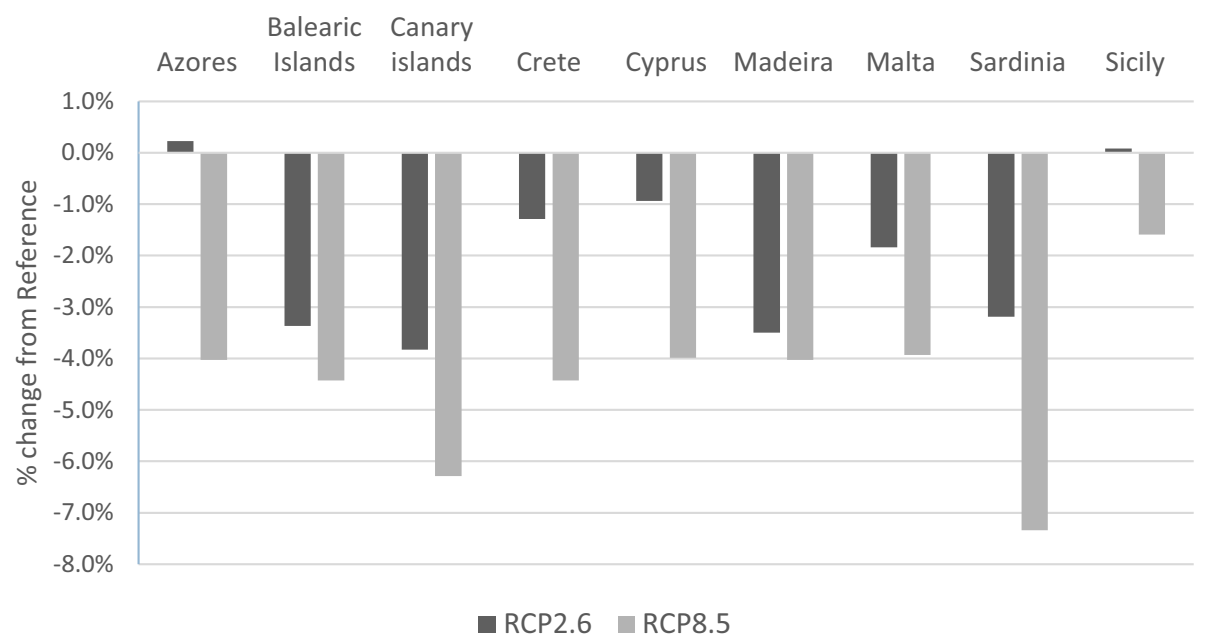

Fig. 6 GDP impacts by island for the aggregate RCP2.6 and RCP8.5 scenario in 2050; source: GINFORS model 
Overall, some islands have higher impacts of climate change on the Blue Economy sectors under both scenarios of climatic conditions, while other islands can expect smaller impacts. The group of islands with higher impacts includes Sardinia, Madeira, Balearics, and the Canaries. The group with moderate impacts is formed by Cyprus, Azores, and Malta, and there is a group with relatively lower impacts formed by Sicily and Crete. We also find two islands with positive GDP impacts for the RCP2.6 scenario, namely the Azores and Sicily. For the Azores, this is partly driven by an increase in agricultural production and comparably low impacts on tourism. For Sicily, high investment needs for additional cooling outweigh smaller consumption losses. Thus, the differences between intensity in the Blue Economy sectors across the islands and their exposure to the damages caused by climate change explain the short- and medium-term variability of GINFORS results of climate change impacts across islands.

\section{Conclusions}

We assess the economic impacts of climate change damages in southern European islands by employing a robust analytical framework consisting of two models with different theoretical underpinnings. Our assessment considers climate impacts on the Blue Economy sectors of tourism, maritime transport, and electricity for two climatic scenarios, namely RCP2.6 and RCP8.5. The expected impacts on coastal zones and islandic ecosystems are estimated to be of a large scale. Sea level rise, changes in precipitation, extreme weather events, and increasing air and sea-surface temperatures can put additional stress on the island communities. What is more, the geographic remoteness of islands jeopardizes their capacity to adapt, and their low economic diversification reduces the resilience to extreme and slow-onset climatic events.

To enhance robustness, the study employs two methodological approaches of applied macroeconomic theories, a CGE and a post-Keynesian macroeconometric model. The combination of these different approaches in a single-impact assessment framework is common in climate mitigation applications for the ex-ante evaluation of climate and energy policies (e.g., European Commission 2020b) and can provide complementary insights for the assessment of climate costs. GDP losses are expected under both climatic scenarios even if a subset of impacts is taken into consideration. The findings are robust and consistent across the two models as the magnitude of results is comparable for most islands. Nevertheless, differences across models and climatic scenarios indicate a range of uncertainty that is inherent to the ex-ante evaluation of macroeconomic impacts of climate change. Uncertainty in this analysis is associated with the differences in socioeconomic outlooks and economic theories of the two models, rather than with the uncertainty linked to the quantification of climate impacts. In future analyses, the consideration of the full distribution of climate hazards, i.e., also considering extreme events, would enhance the comprehension of the uncertainty space. Incorporating the impacts of tipping points would also allow for a consideration of extreme events, with low probability but high impact.

Economic losses under the RCP8.5 scenario are significantly higher and are more pronounced in the long term with the intensification of climate impacts. Our findings indicate that islands are particularly vulnerable to climate-related damages, both due to their geographic remoteness and their low economic diversification. The effects of climate change on the tourism sector are detrimental to the islandic economies, given the sector's complex value chain and dominant position in value added. Geographically 
remote islands face an additional challenge due to higher electricity demand for cooling and desalination which adds pressure to the limited resources of the economy and hinders their competitiveness. A key example is the increasing electricity demand for cooling and desalination that, if needed to be met domestically, adds an important pressure to the limited resources of the islandic economy. We note, however, that the analysis focuses on islands located in the Mediterranean and the Atlantic and can thus provide limited insights for northern islands.

Our assessment describes the economic costs that the southern European islands could face if anticipatory and adaptation measures are not undertaken. To this end, we highlight the importance of downscaling the assessment of climate costs to the regional level when aiming to inform the decision-making process and to better target adaptation policies. This downscaling implies access to detailed regional economic and climatic data. Future research can expand the macroeconomic assessment of climate damages on islands to further economic activities, beyond the Blue growth sectors, and to the evaluation of the benefits of tailored adaptation policies and strategies designed to counteract the expected impacts of climate change. In addition, future research can investigate the influence of labor force and overall population migration due to climate change as well as the availability of capital transfers from other regions as alternative financing options. This type of analysis would enhance the flexibility of the system to respond to climate impacts, thus increase its adaptive capacity, and would require a multiregional spatial general equilibrium model to allow for identification of regional specificities such as price fluctuations or changes in terms of change, and is subject to data availability (e.g., climate impacts for the rest of the regions).

Our findings add to the literature that calls for immediate ambitious mitigation policies. While economic costs are still relevant for a RCP2.6 emission trajectory, GDP losses in some islands more than doubled in the RCP8.5 scenario. Strong synergies can be identified with the implementation of adaptation and mitigation policies. For example, policies that foster energy efficiency and the penetration of dispersed renewable energy plants can further enhance the adaptive capacity of the islands against the increasing electricity demand for cooling and desalination. To this end, the Blue Economy strategy, part of the EU Green Deal, provides the enabling conditions to develop green infrastructure in coastal areas and develop offshore renewable energy.

Supplementary Information The online version contains supplementary material available at https://doi. org/10.1007/s10584-022-03310-5.

Author contribution Z.V., U.L., C.L., and L.P. conceived the research scope and developed the framework. I.C and M.M ran the macroeconomic simulations (GEM-E3-ISL and GINFORS respectively) and prepared the new island databases. Z.V., C.L., I.C., Y.L., and C.L. wrote the manuscript. Z.V. revised the manuscript after comments by reviewers. A.A. provided the TSA data. A.A., Y.L., and M.G. contributed to the evaluation of impact chains as inputs for the model.

Funding Research in this paper has received funding from the European Union's Horizon 2020 research and innovation programme under Grant Agreement No776661, project SOCLIMPACT - "Downscaling climate impacts and decarbonisation pathways in EU Islands, and enhancing socioeconomic and non-market evaluation of Climate Change for Europe, for 2050 and beyond".

Data availability Data linked to figures, or the new island-level databases developed for the purposes of this paper are available upon request.

Materials availability Not applicable.

Code availability Not available. 


\section{Declarations}

Conflict of interest The authors declare no competing interests.

\section{References}

Aguiar A, Chepeliev M, Corong E, McDougall R, van der Mensbrugghe D (2019) The GTAP Data Base: Version 10. J Glob Econ Anal 4(1):1-27 (Retrieved from https://www.jgea.org/ojs/index.php/jgea/artic le/view/77)

Arabadzhyan A, Figini P, García C, González MM, Lam-González YE, León CJ (2020) Climate change, coastal tourism, and impact chains-a literature review. Curr Issues Tour 24:1-36

Bennett NJ, Cisneros-Montemayor AM, Blythe J, Silver JJ, Singh G, Andrews N, ..., Sumaila UR (2019) Towards a sustainable and equitable blue economy. Nature Sustain 2(11):991-993

Bosello F, Parrado R (2020) Macro-economic assessment of climate change impacts: methods and findings. Ekon: Rev Vasca Econ 97:44-61

Capros P, Van Regemorter D, Paroussos L, Karkatsoulis P, Fragkiadakis C, Tsani S, ..., Abrell J (2013) GEM-E3 model documentation. JRC Sci Pol Rep 26034:158

Capros P, Paroussos L, Fragkos P, Tsani S, Boitier B, Wagner F, ..., Bollen J (2014) Description of models and scenarios used to assess European decarbonisation pathways. Energ Strat Rev 2(3-4):220-230

Christodoulou A, Christidis P, Demirel H (2019) Sea-level rise in ports: a wider focus on impacts. Marit Econ Logist 21:482-496. https://doi.org/10.1057/s41278-018-0114-Z

Ciscar JC, Iglesias A, Feyen L, Szabó L, Van Regemorter D, Amelung B, ..., Soria A (2011) Physical and economic consequences of climate change in Europe. Proc Natl Acad Sci 108(7):2678-2683

Ciscar JC, Szabó L, Van Regemorter D, Soria A (2012) The integration of PESETA sectoral economic impacts into the GEM-E3 Europe model: methodology and results. Clim Change 112(1):127-142

Ciscar JC, Feyen L, Soria A, Lavalle C, Raes F, Perry M, ..., Ibarreta D (2014) Climate impacts in EuropeThe JRC PESETA II project

Distelkamp M, Meyer M (2019) Pathways to a resource-efficient and low-carbon Europe. Ecol Econ 155:88-104

E3Modelling (2017). GEM-E3 Model manual. https://e3modelling.com/modelling-tools/gem-e3/. Accessed 10 Oct 2021

European Commission (2017) The 2018 Ageing Report. INSTITUTIONAL PAPER 065 I NOVEMBER 2017. Available in https://ec.europa.eu/info/sites/default/files/economy-finance/ip065_en.pdf

European Commission (2020a). The EU Blue Economy Report. 2020. Publications Office of the European Union. Luxembourg.

European Commission (2020b) Impact Assessment accompanying the document "Communication from the Commission to the European Parliament, the CVouncil, the European Economic and social commitee and the Committee of the regions: Stepping up Europe's 2030 climate ambition Investing in a climateneutral future for the benefit of our people". Available in https://ec.europa.eu/clima/sites/clima/files/ eu-climate-action/docs/impact_en.pdf

European Commission (2021) Commission Staff Working Document Impact Assessment Report Accompanying the document Communication from the Commission to the European Parliament, the Council, the Economic and social Committee and the Committee of the Regions Forging a climate-resilient Europe - The new EU Strategy on Adaptation to Climate Change, Brussels, 24.2.2021, SWD(2021) 25 final. SWD/2021/25 final https://eur-lex.europa.eu/legal-content/EN/TXT/?uri=SWD:2021:25:FIN

Feyen L, Ciscar JC, Gosling S, Ibarreta D, Soria A (editors) (2020) Climate change impacts and adaptation in Europe. JRC PESETA IV final report. EUR 30180EN, Publications Office of the European Union, Luxembourg, ISBN 978-92-76-18123-1, https://doi.org/10.2760/171121, JRC119178

Hampton MP, Jeyacheya J (2020) Tourism-dependent small islands, inclusive growth, and the Blue Economy. One Earth 2(1):8-10

Hein E (2017) Post-Keynesian macroeconomics since the mid-1990s: main developments. Euro J Econ Econ Pol: Interv 14(2):131-172

IEA (2019) World Energy Balances 2019, Paris 2019

IPCC (2012) Managing the risks of extreme events and disasters to advance climate change adaptation. In: Field CB, Barros V, Stocker TF, Qin D (eds) Special Report of the Intergovernmental Panel on Climate Change. Cambridge University Press, Cambridge (http://ipcc-wg2.gov/SREX/report/)

Jorda G, Marbà N, Bennett S, Santana-Garcon J, Agusti S, Duarte CM (2020) Ocean warming compresses the three-dimensional habitat of marine life. Nature Ecol Evol 4(1):109-114 
Karkatsoulis P, Siskos P, Paroussos L, Capros P (2017) Simulating deep CO2 emission reduction in transport in a general equilibrium framework: The GEM-E3T model. Transp Res Part d: Transp Environ 55:343-358

Kelman I (2018) Islandness within climate change narratives of small island developing states (SIDS). Island Stud J 13(1):149-166

Kelman I, Orlowska J, Upadhyay H, Stojanov R, Webersik C, Simonelli AC, ..., Němec D (2019) Does climate change influence people's migration decisions in Maldives? Clim Change 153(1):285-299

Lazrus H (2012) Sea change: island communities and climate change. Annu Rev Anthropol 41:285-301

Lee KH, Noh J, Khim JS (2020) The Blue Economy and the United Nations' sustainable development goals: challenges and opportunities. Environ Int 137:105528

León CJ, Lam-González YE, Galindo CG, Hernández MMG (2020) Measuring the impact of infectious diseases on tourists' willingness to pay to visit island destinations. Atmosphere 11(10):1117

Linkov I, Fox-Lent C, Keisler J, Della Sala S, Sieweke J (2014) Risk and resilience lessons from Venice. Environ Syst Decis 34(3):378-382

Lutz C, Meyer B (2009) Environmental and economic effects of post-Kyoto carbon regimes: results of simulations with the global model GINFORS. Energy Policy 37(5):1758-1766

Lutz C, Meyer B, Wolter MI (2010) The global multisector/multicountry 3-E model GINFORS. A description of the model and a baseline forecast for global energy demand and CO2 emissions. Int J Glob Environ Issues 10(1-2):25-45

Lutz C, Lehr U, Wiebe KS (2012) Economic effects of peak oil. Energy Policy 48:829-834

Memobust (2014) Memobust handbook on methodology of modern business statistics. Available here https://ec.europa.eu/eurostat/cros/system/files/Macro-Integration-03-M-RAS\%20v1.0.pdf

Mercure J-F, Knobloch F, Pollitt H, Paroussos L, Scrieciu S, Lewney R (2019) Modelling innovation and the macroeconomics of low-carbon transitions: theory, perspectives and practical use. Climate Policy 19(8):1019-1037. https://doi.org/10.1080/14693062.2019.1617665

Meyer M, Charalampidis I, Vrontisi Z, Lehr U (2019) Deliverable 6.1.R Updated Database of Islands: Methodological framework. SOCLIMPACT project. Available at https://ec.europa.eu/research/parti cipants/documents/downloadPublic?documentIds=080166e5cabe71a8\&appId=PPGMS. Accessed 10 Oct 2021

Meyer B, Ahlert G (2019) Imperfect Markets and the Properties of Macro-economic-environmental Models as Tools for Policy Evaluation. Ecol Econ 155:80-87. https://doi.org/10.1016/j.ecolecon. 2017.06.017

Mcleod E, Bruton-Adams M, Förster J, Franco C, Gaines G, Gorong B, ..., Terk E (2019) Lessons from the Pacific islands-adapting to climate change by supporting social and ecological resilience. Front Mar Sci 6:289

McMillen HL, Ticktin T, Friedlander A, Jupiter SD, Thaman R, Campbell J, ..., Orcherton DF (2014) Small islands, valuable insights: systems of customary resource use and resilience to climate change in the Pacific. Ecol Soc 19(4):17

Meyer B, Meyer M, Distelkamp M (2012) Modeling green growth and resource efficiency: new results. Miner Econ 24(2-3):145-154

Meyer M, Hirschnitz-Garbers M, Distelkamp M (2018) Contemporary resource policy and decoupling trends - lessons learnt from integrated model-based assessments. Sustainability 10(6):1858. https:// doi.org/10.3390/su10061858

Nikas A, Doukas H, Papandreou A (2019) A detailed overview and consistent classification of climateeconomy models. In: Doukas H, Flamos A, Lieu J (eds) Understanding Risks and Uncertainties in Energy and Climate Policy. Springer, Cham. https://doi.org/10.1007/978-3-030-03152-7_1

Nordhaus W (2017) Integrated assessment models of climate change. NBER Report 3:16-20

OECD (2019) Input-Output Tables. URL: http://www.oecd.org/sti/ind/input-outputtables.htm [retrieved on January 23 2020].

Ourbak T, Magnan AK (2018) The Paris Agreement and climate change negotiations: small islands, big players. Reg Environ Change 18(8):2201-2207

Paroussos L, Mandel A, Fragkiadakis K, Fragkos P, Hinkel J, Vrontisi Z (2019a) Climate clubs and the macro-economic benefits of international cooperation on climate policy. Nat Clim Chang 9:542546. https://doi.org/10.1038/s41558-019-0501-1

Paroussos L, Vrontisi Z, Charalampidis I et al. (2019b) Deliverable 6.2 Macroeconomic outlook for the islands' economic systems and pre testing simulations. SOCLIMPACT project. https://soclimpact. net/wp-content/uploads/2020/02/23-D6.2-Macroeconomic-outlook-for-the-islands.pdf

Planistat Europe (2003) Analysis of the island regions and outermost regions of the European Union, Part I: The island regions 
Pollitt H, Mercure JF (2018) The role of money and the financial sector in energy-economy models used for assessing climate and energy policy. Clim Pol 18(2):184-197

Primo C, Keleman FD, Obermann A, Ahrens B (2018) The effect of coupled marginal seas on precipitation extremes and heat waves in 20th century CCLM simulation. In CLM-Assembly 2018 Conference proceedings, p. 20.

Ruiz-Salmón I, Margallo M, Laso J, Villanueva-Rey P, Mariño D, Quinteiro P, ..., Aldaco R (2020) Addressing challenges and opportunities of the European seafood sector under a circular economy framework. Curr Opin Environ Sci Health 13:101-106

Russell JC, Kueffer C (2019) Island biodiversity in the Anthropocene. Annu Rev Environ Resour 44:31-60

Sarker S, Bhuyan MAH, Rahman MM, Islam MA, Hossain MS, Basak SC, Islam MM (2018) From science to action: exploring the potentials of Blue Economy for enhancing economic sustainability in Bangladesh. Ocean Coast Manag 157:180-192

Sarker MNI, Wu M, Alam GM, Shouse RC (2020) Life in riverine islands in Bangladesh: Local adaptation strategies of climate vulnerable riverine island dwellers for livelihood resilience. Land Use Pol 94:104574

Schinko T, Drouet L, Vrontisi Z, Hof A, Hinkel J, Mochizuki J, ..., Lincke D (2020) Economy-wide effects of coastal flooding due to sea level rise: a multi-model simultaneous treatment of mitigation, adaptation, and residual impacts. Environ Res Commun 2(1):015002. https://doi.org/10.1088/2515-7620/ ab6368

Smith-Godfrey S (2016) Defining the blue economy. Marit Aff: J Natl Marit Found India 12(1):58-64

Spalding MJ (2016) The new blue economy: the future of sustainability. J Ocean Coast Econ 2(2):8

Taylor S, Kumar L (2016) Global climate change impacts on pacific islands terrestrial biodiversity: a review. Trop Conserv Sci 9(1):203-223

Veron S, Mouchet M, Govaerts R, Haevermans T, Pellens R (2019) Vulnerability to climate change of islands worldwide and its impact on the tree of life. Sci Rep 9(1):1-14

Vrontisi Z, Charalampidis I, Paroussos L (2020) What are the impacts of climate policies on trade? A quantified assessment of the Paris Agreement for the G20 economies. Energy Pol 139:111376

Vrontisi Z, Fragkiadakis K, Kannavou M et al (2020b) Energy system transition and macroeconomic impacts of a European decarbonization action towards a below $2{ }^{\circ} \mathrm{C}$ climate stabilization. Clim Change 162:1857-1875. https://doi.org/10.1007/s10584-019-02440-7

Weir T, Dovey L, Orcherton D (2017) Social and cultural issues raised by climate change in Pacific Island countries: an overview. Reg Environ Change 17(4):1017-1028

Wiebe KS, Lutz C (2016) Endogenous technological change and the policy mix in renewable power generation. Renew Sustain Energy Rev 60:739-751. https://doi.org/10.1016/j.rser.2015.12.176

Publisher's Note Springer Nature remains neutral with regard to jurisdictional claims in published maps and institutional affiliations. 